\title{
Mitigation of Unbalanced Voltage Sag by using Custom Power Devices
}

\author{
Miss Manjusha D. Hedau, , Mr. Harish D. Mude², Miss Pallavi V. Pullawar ${ }^{3}$ \\ Assistant Professor, Department of Electrical Engineering, Jagadambha College of Engineering, Yavatmal, India ${ }^{1,2,3}$
}

\begin{abstract}
Unbalanced Voltage sag is literally one of power quality problem and it become severe to industrial customers. Voltage sag can cause miss operation to several electronic equipments. That problem can be mitigating with voltage injection method using custom power device, Dynamic Voltage Restorer (DVR). This paper presents modelling and analysis of a DVR using Matlab/Simulink. The performance of the DVR depends on the efficiency of the control technique involved in switching the inverter. This paper proposed two control techniques which is PI Controller (PI) and Fuzzy Logic Controller (FL) kalman filter. Comprehensive results are presented to assess the performance of each controller as the best power quality solution. Other factors that also can affect the performance and capability of DVR are presented as well.
\end{abstract}

Keywords: Voltage sag; Dynamic Voltage Restore; Pulse Width Modulation (PWM); PI Controller; Fuzzy Logic Controller Unbalanced voltage sag, Kalman filter.

\section{INTRODUCTION}

Recently, power quality problems become a major sum of the error (difference between output and and concern of industries due to massive loss in terms of time desired set-point) and the integral of that value.

and money. Hence, there are always demands for good power quality, which positively resulting in reduction of power quality problems like voltage sag, harmonic and flicker [1]. Voltage sag is always considered as one of the major power quality problems because the frequency of occasion is so high. Moreover, according to the data recorded by Tenaga Nasional Berhad (TNB), $80 \%$ of power quality complaints by consumers in Malaysia were outlined to be associated with voltage sag [2]. The common causes of voltage sag are faults or short circuit in the system, starting of large loads and faulty wiring [3]. This will been widely used in the power system due to the lead to increase in both production and financial loss for reliability to maintain power quality control industries. Therefore, it is vital to mitigate voltage sag.

Two main characteristics that explain the voltage sag are depth/magnitude and duration of voltage sag itself. The depth/magnitude and duration of voltage drop that said to be voltage sag is between 0.1 to $0.9 \mathrm{pu}$ with time interval, $t$ about 0.5 cycle to 1 minite One of the most FACTS devices that have been created in improvement the performance of power quality is Dynamic Voltage Restorer (DVR) also known as custom power devices.

Control unit is the heart of the DVR where it main function is to detect the presence of voltage sags in the system, calculating the required compensating voltage for the DVR and generate the reference voltage for PWM generator to trigger on the PWM inverter. The components of control system unit are the dq0-transformation, Phase-lock-loop (PLL) and the PI or FL Controller. PI Controller is a feedback controller which drives the plant to be controlled with a weighted

$$
\begin{gathered}
\mathrm{V}_{\mathrm{DVR}}=\mathrm{V}_{\mathrm{L}}+\mathrm{Z}_{\mathrm{th}} \mathrm{I}-\mathrm{V}_{\mathrm{th}}(1) \\
\mathrm{I}_{\mathrm{L}}=\left[\mathrm{P}_{\mathrm{L}}+\mathrm{jQ}_{\mathrm{L}} / \mathrm{V}_{\mathrm{L}}\right]
\end{gathered}
$$

0.5 cycles to 1 minute [4]. This classification is based on IEEE Line voltage Vabc (p.u) Convert to dq0 term Set dq references Compare

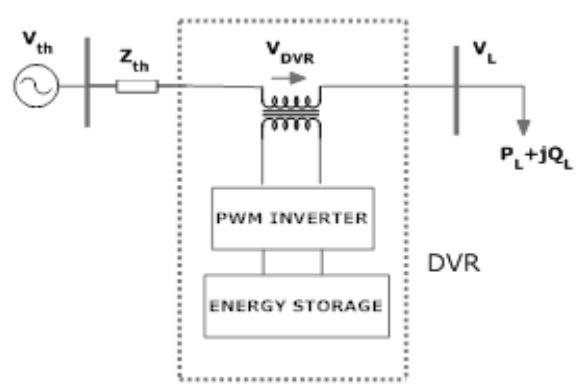

Figure 1. Calculation for DVR voltage injection 
If $\mathrm{V}_{\mathrm{L}}$ is considered as a reference;

$$
\mathrm{V}_{\mathrm{DVR}} \angle \alpha=\mathrm{V}_{\mathrm{L}} \angle 0+\mathrm{Z}_{\text {th }} \mathrm{I}_{\mathbf{L}} \angle(\beta-\theta)-\mathrm{V}_{\text {th }} \angle \delta
$$

Here $\mathrm{I}$, ü, and $\mathrm{i}$ are the angle of $\mathrm{V}_{\mathrm{DVR}}, \mathrm{Z}_{\mathrm{th}}$ and $\mathrm{V}_{\mathrm{th}}$, respectively and s is the load power factor angle with

$$
\theta=\tan ^{-}(\mathrm{P} / \mathrm{Q})
$$

Thus, the power injection of the DVR can be written as

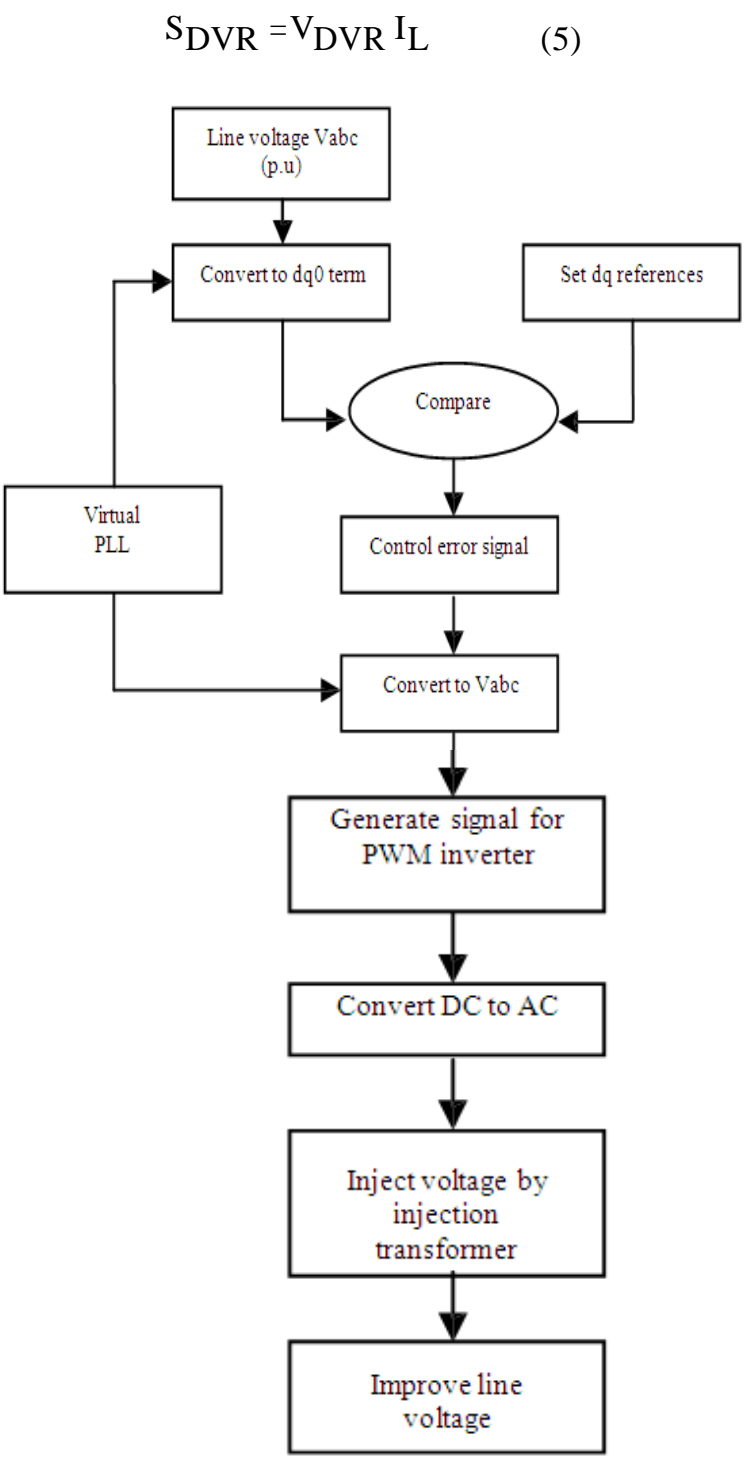

Figure 2. Flow chart of DVR operation

\section{B. Principal of Operation}

The basic function of DVR is to inject dynamically voltage required, VDVR to compensate sagging occurrence. Generally, the operation of DVR can be categorized into two modes; standby mode and injection mode [6]. In standby mode, DVR either in short circuited operation or inject small voltage to cover voltage drop due to transformer reactance losses. The
DVR is turn into injection mode as soon as sagging is detected. VDVR is injected in series with load with required magnitude and phase for compensation.

\section{Modelling of DVR}

Fig. 2 shows the flow chart of basic concept of the DVR operation. Typical DVR is built in Matlab/Simulink program as depicted in Fig. 3. The study considered the standard voltage used in Malaysia, supplied by Tenaga Nasional Berhad (TNB). The source is $11 \mathrm{kV}$ fed from TNB distribution substation (PPU). $11 \mathrm{kV}$ is then cabled to step down transformer, convert the $11 \mathrm{kV}$ voltage to $415 \mathrm{~V}$ before deliver it to consumer's load. In this study, we applied two example of load, Load 1 and Load 2. Load 2 represents the non-sensitive equipment which means that the equipment can tolerate the sagging condition. Meanwhile, Load 1 represents the sensitive equipment like ASDs and PLCs where voltage regulation is crucial. Thus, DVR will be inserted in series with Load 1 to help improving the supply voltage before to be fed by Load 1 .

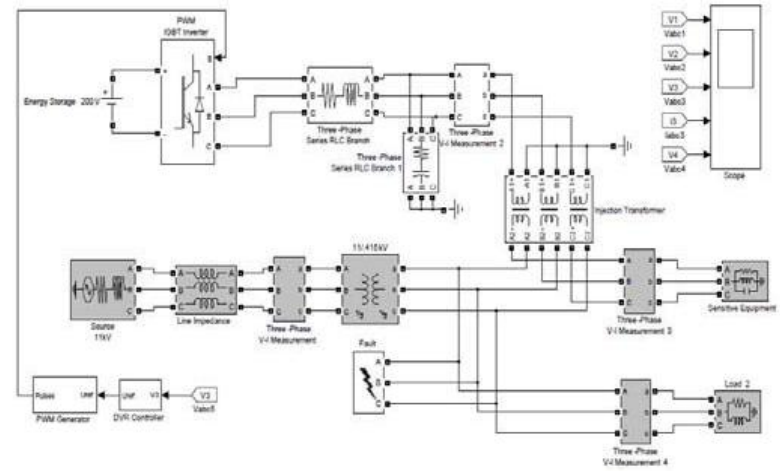

Figure34. DVR Modelling using Matlab/Simulink

Three legs PWM inverter is used to convert DC source to $\mathrm{AC}$ voltage and then injected into the line by injection transformer. The inverter model consists of selfcommutating IGBT switches with parallel diodes. The sinusoidal pulse width modulation technique (PWM) forms the control strategy. The control block generates the firing signals for each switch with controllable amplitude, phase and frequency whenever sag is detected. The filter unit is applied to output of the inverter as it is closer to harmonic source.

\section{DVR Control Techniques}

The fundamental roles of a controller in a DVR are to detect the voltage sag occurrences in the system; calculate the compensating voltage, to generate trigger pulses of PWM inverter and stop triggering pulses when the occurrence has passed. Using RMS value calculation of the voltage to analyze the sags does not give fast result. In this study, the dq0 transformation or Park's transformation is used in voltage calculation. The dq0 transformation is a transformation of coordinates from the three-phase stationary coordinate system to the dq 
rotating coordinate system [7]. This dq0 method gives All the gains selected use to tune up the error signal d the information of the depth (d) and phase shift $(\mathrm{q})$ of and $\mathrm{q}$ so that the signal is stable and well responses to voltage sag with start and end time. system disturbances. The outputs of the PI controller then are transformed back into Vabc before forwarded to

After conversion, the three-phase voltage $\mathrm{Va}, \mathrm{Vb}$ and $\mathrm{Vc}$ PWM generator. become two constant voltages $\mathrm{Vd}$ and $\mathrm{Vq}$ and now, they are easily controlled. In this paper, two control techniques have been proposed which are proportional integral (PI) controller and fuzzy logic (FL) controller. Comprehensive results are presented to assess the performance of each controller as the best power quality solution.

\section{1) Proportional-Integral (PI) Controller}

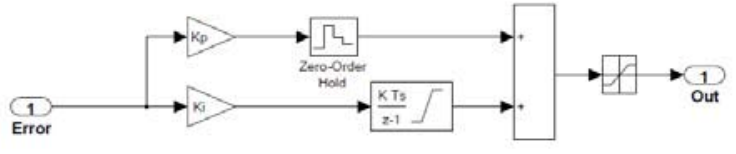

Figure 4 Discrete PI controller

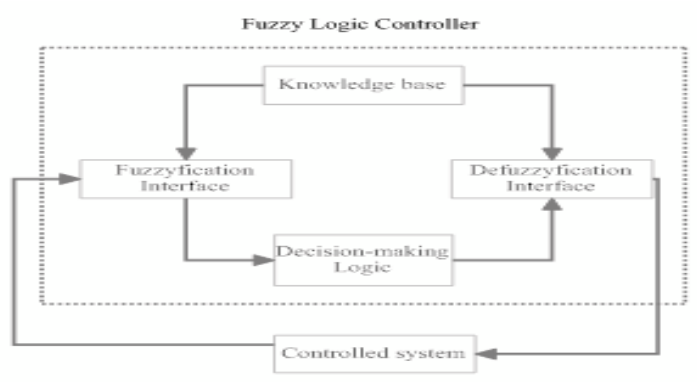

Figure 6. Basic configuration of FL controller

Unlike Boolean logic, fuzzy logic allows states (membership values) between 0 or 1 . Its major features are the use of linguistic variables rather than numerical PI Controller shown in Fig. 4 is a feedback controller variables. Linguistic variables, defined as variables which drives the plant to be controlled with a weighted whose values are sentences in a natural language (such sum of the error and the integral of that value [8]. The as small and big), may be represented by fuzzy sets [9]. proportional response can be adjusted by multiplying the The general structure of an FLC is represented in Fig. 6 error by constant KP, called proportional gain. The and comprises four principal components:

contribution from integral term is proportional to both the magnitude of error and duration of error. The error is first multiplied by the integral gain, $\mathrm{Ki}$ and then was integrated to give an accumulated offset that have been corrected previously [8].

Fig.5 shows the control circuit designed in Matlab/Simulink. The input of the controller come from the output voltage, V3 measured by three-phase V-I measurement at Load 1 in pu. V3 is then transformed in $\mathrm{dq}$ term (expressed as instantaneous space vector). The voltage sag is detected by measuring the error between the dq-voltage and the reference values. The d-reference is set to rated voltage whilst q- reference is set to zero. The dq components of load voltage are compared with the reference values and the error signal is then entering to PI controller. Two PI controller block are used for error signal-d and error signal-q separately. For error signal-d, KP is set to 40 and $\mathrm{Ki}$ is set to 154 whilst for error signal-q, KP and $\mathrm{Ki}$ is set to 25 and 260 respectively.

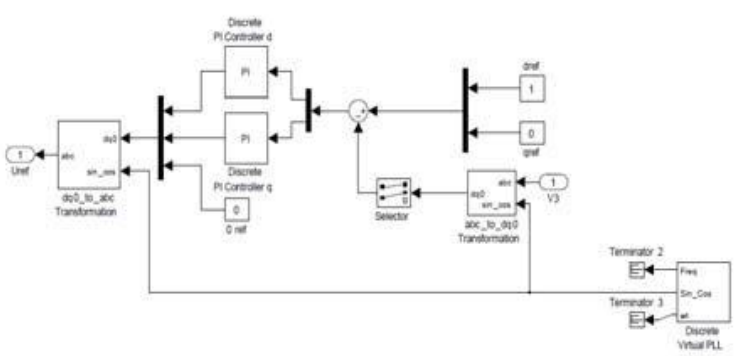

Figure 5. Control circuit using PI controller
- a fuzzyfication interface which converts input data into suitable linguistic values; a knowledge base which consists of a data base with the necessary linguistic definitions and control rule set;

- a decision making logic which, simulating a human decision process infers the fuzzy control action from - the knowledge of the control rules and the linguistic variable definitions; and

- a defuzzification interface which yields a nonfuzzy control action from an inferred fuzzy control action.

In this paper, two FL controller block are used for error signal-d and error signal-q as shown in Fig.7. The process also same as before except the controller now is Fuzzy Logic. For both blocks (error signal-d and q) the FL controller consists of 8 linguistic variables from input which is; Negative (N), Zero (Z), Positive Small (PS), Positive Fair Small (PFS), Positive Average (PA), Positive Fair Big (PFB), Positive Big (PB), and Positive Very Big (PVB).

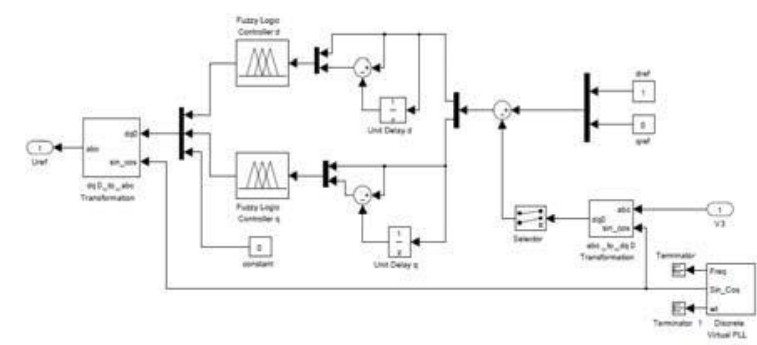

Figure 7. Control circuit using FL controller 
IJIREEICE

ISO 3297:2007 Certified

Vol. 5, Issue 1, January 2017

Each parameter from linguistic variables for error signal is shown in Fig.8. For delta error, there are two linguistic variables Negative $(\mathrm{N})$ and Positive $(\mathrm{P})$. Both variables can be depicted as in Fig. 9.

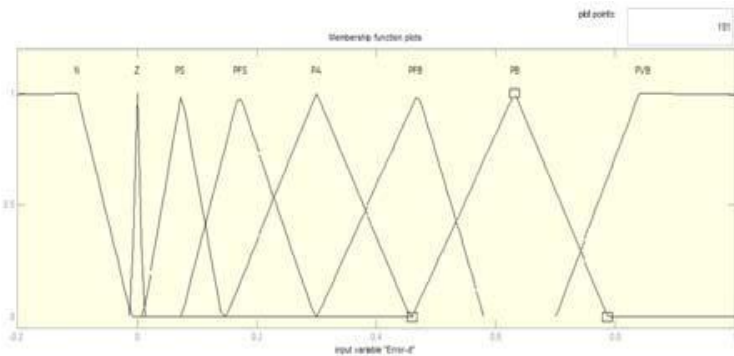

Figure 8. Linguistic variables from input

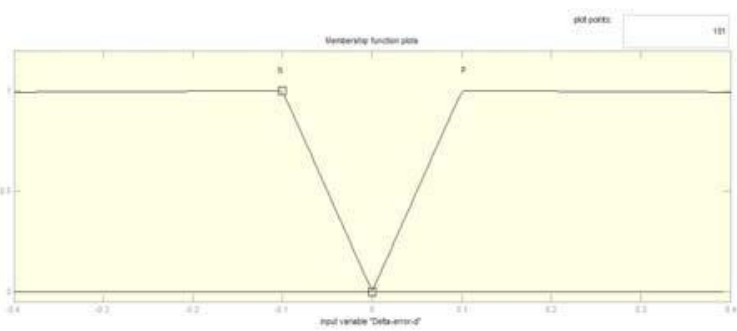

Figure 9. Linguistic variables from delta error

In defuzzyfication process, there are 13 linguistic variables which are Negative $(\mathrm{N})$, Zero (Z), Positive Small 1 (PS1), Positive Small 2 (PS2), Positive Fair Small 1 (PFS1), Positive Fair Small 2 (PFS2), Positive Average 1 (PA1), Positive Average 2 (PA2), Positive Fair Big1 (PFB1), Positive Fair Big 2 (PFB2), Positive Big1 (PB1), Positive Big 2 (PB2) and Positive Very Big (PVB). Fig.10 shows each parameter for output signal.

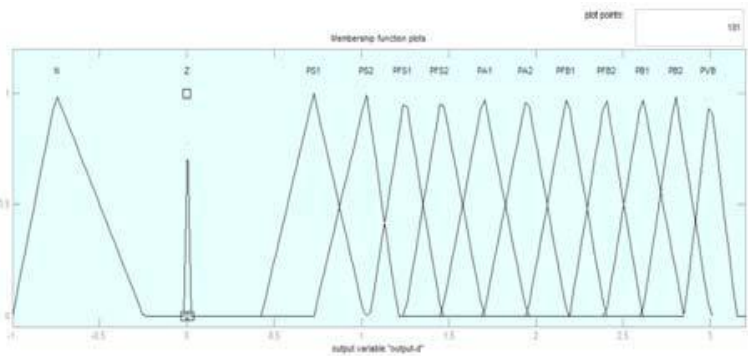

Figure 10. Linguistic variables from output signal

TABLE I. RULE BASE

\begin{tabular}{|c|c|c|l|l|l|l|l|l|}
\hline $\begin{array}{c}\text { E } \\
\text { DE }\end{array}$ & $\mathbf{N}$ & $\mathbf{Z}$ & PS & PFS & PA & PFB & PB & PVB \\
\hline $\mathbf{N}$ & N & Z & PS1 & PFS1 & PA1 & PFB1 & PB1 & PVB \\
\hline P & N & Z & PS2 & PFS2 & PA2 & PFB2 & PB2 & PVB \\
\hline
\end{tabular}

In the decision-making process, there is rule base that linking between input (error signal) and output signal. Table 1 show the rule base used in this FL controller.

\section{RESULTS AND DISCUSSIONS}

\section{A. Fault Analysis}

Simulation of voltage sag disturbance on the industrial electricity system is done by generating fault using 3 -phase fault generator at load 2 until load 1 (sensitive equipment) are affected too by sag phenomenon. DVR are inserted to industrial electricity system, load 1. Two types of fault generated at load 2 to produce sag phenomenon which is double-line-toground fault (unbalanced) and balanced three phase fault. There are four levels of voltage generated to load 1 for every fault ( 0.02 to 0.07 seconds duration) which are $30 \%, 50 \%, 80 \%$ and $90 \%$ voltage sags. Both PI and FL Controller are simulated and performance of DVR is analyzed to determine how it deals with all type of fault and which controller gives better efficiency.

1) Double-line-to-ground fault with $50 \%$ sagging

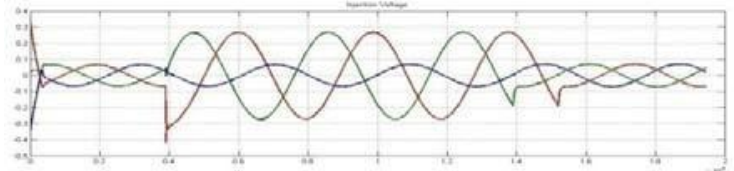

(a)

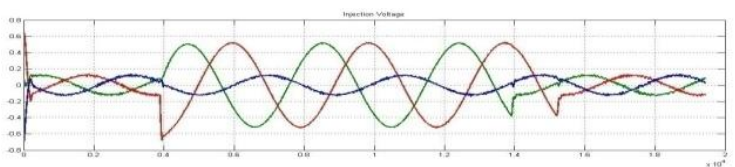

(b)

Figure 11. (a) Injection voltage from DVR controlled by PI; (b) injection voltage controlled by FL

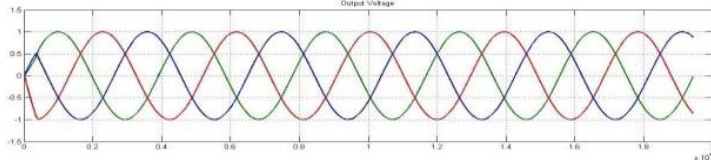

(a)

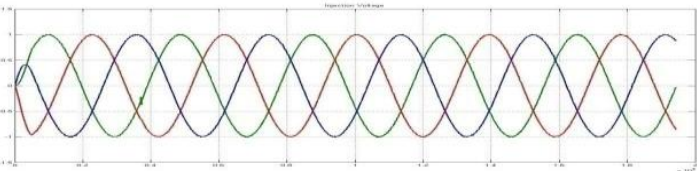

(b)

Figure 12. (a) Output voltage at load 1 after injection voltage from DVR controlled by PI; (b) Output voltage at load 1 after injection voltage controlled by FL.

2) Balanced three-phase fault with $50 \%$ sagging

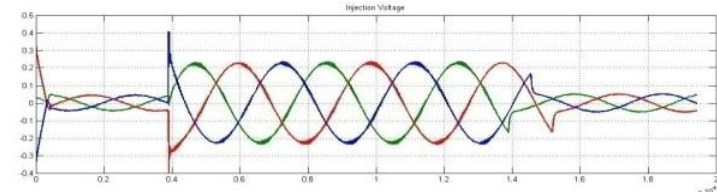

(a) 
Vol. 5, Issue 1, January 2017

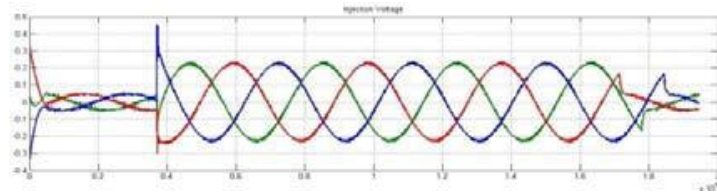

(b)

Figure 13. (a) Injection voltage from DVR controlled by PI; (b) injection voltage controlled by FL.

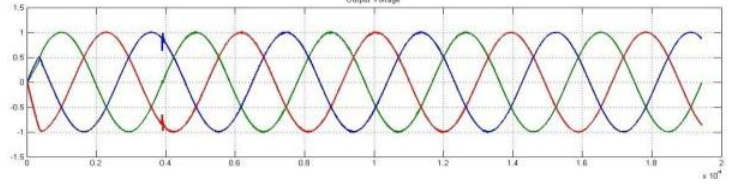

(a)

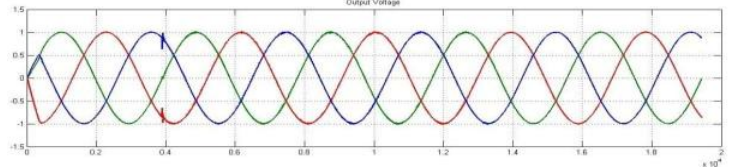

(b)

Figure 14. (a) Output voltage at load 1 after injection voltage from DVR controlled by PI; (b) Output voltage at load 1after injection voltage controlled by FL.

Fig. 11 to 14, shows that, the moment where fault occurred at load 2, resultant in sag happened at load 1 as dip as $50 \%$ voltage drop. Table II and Table III show the comparison of the output voltage as a result due to voltage injection from DVR controlled by PI and FL for each phase in four levels of voltage sag. It can be seen that both controllers gave an optimum performance and have the ability to improve the source voltage back to 1 p.u before deliver it to the load in balanced and unbalanced fault condition. Even for worst case, balanced three phase fault with 0.1 p.u voltage sag, DVR controlled by PI and FL still can work successfully. However, PI Controller generates higher total harmonic distortion (THD), $1.68 \%$ as compared to FL Controller, $0.64 \%$ as shown in Fig. 15 and 16.

TABLE II. DOUBLE-LINE-TO-GROUND FAULT

\begin{tabular}{|c|c|c|c|c|c|c|c|c|c|}
\hline \multirow{2}{*}{$\begin{array}{c}\text { Sag } \\
(\%)\end{array}$} & \multicolumn{3}{|c|}{$\begin{array}{c}\text { Before } \\
\text { Injection (\%) }\end{array}$} & \multicolumn{2}{|c|}{$\begin{array}{c}\text { Injection DVR } \\
\text { PI Controller } \\
(\%)\end{array}$} & \multicolumn{2}{|c|}{$\begin{array}{c}\text { Injection DVR } \\
\text { FL Controller } \\
(\%)\end{array}$} \\
\cline { 2 - 10 } & $\mathbf{A}$ & $\mathbf{B}$ & $\mathbf{C}$ & A & B & C & A & B & C \\
\hline $\mathbf{3 0}$ & 70.6 & 70.4 & 10 & 99.4 & 99.4 & 10 & 100. & 100. & 100 \\
\hline $\mathbf{5 0}$ & 51.5 & 51.0 & 10 & 99.2 & 99.8 & 10 & 100. & 99.9 & 100 \\
\hline $\mathbf{8 0}$ & 20.6 & 20.4 & 10 & 100 & 100. & 10 & 100. & 100. & 100 \\
\hline $\mathbf{9 0}$ & 1 & 10.1 & 100 & 99.9 & 100. & 10 & 99.9 & 100. & 100 \\
\hline
\end{tabular}

TABLE III. BALANCED THREE PHASE FAULT

\begin{tabular}{|c|c|c|c|c|c|c|c|c|c|}
\hline $\begin{array}{c}\text { Sag } \\
(\boldsymbol{\%})\end{array}$ & $\begin{array}{c}\text { Before Injection } \\
(\%)\end{array}$ & \multicolumn{2}{|c|}{$\begin{array}{c}\text { Injection DVR } \\
\text { PI Controller }\end{array}$} & \multicolumn{4}{|c|}{$\begin{array}{c}\text { Injection DVR Controller } \\
\text { FL }\end{array}$} \\
\cline { 2 - 9 } & A & B & C & A & B & C & A & B & C \\
\hline
\end{tabular}

\begin{tabular}{|c|c|c|c|c|c|c|c|c|c|}
\hline $\mathbf{3 0 \%}$ & 70.64 & 70.59 & 70.65 & 99.83 & 100.3 & 100.2 & 100.1 & 100.2 & 100.1 \\
\hline $\mathbf{5 0 \%}$ & 51.02 & 50.97 & 50.94 & 99.74 & 99.82 & 99.72 & 100.2 & 100.1 & 100.2 \\
\hline $\mathbf{8 0 \%}$ & 20.13 & 19.76 & 19.66 & 99.56 & 99.55 & 99.63 & 100 & 100.2 & 100.4 \\
\hline $\mathbf{9 0 \%}$ & 10 & 9.98 & 10.1 & 100.2 & 100.4 & 100.1 & 100 & 100.1 & 100.1 \\
\hline
\end{tabular}

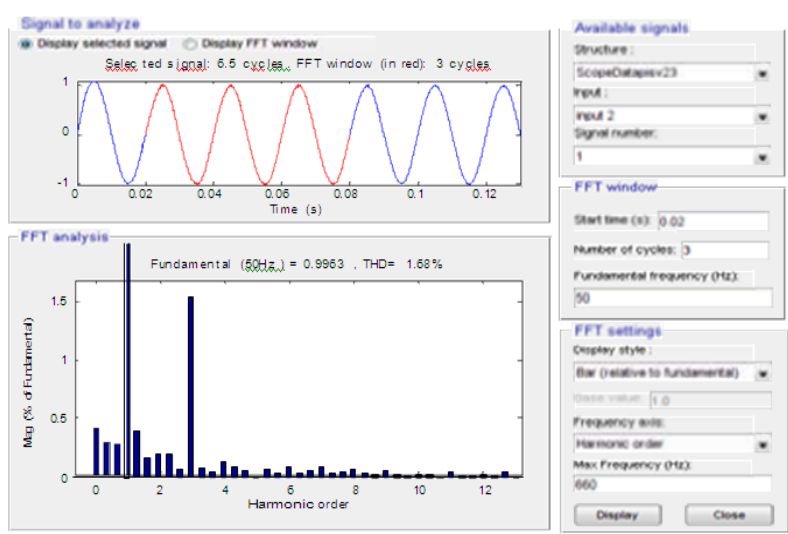

Figure 15. THD generated when PI controller is applied

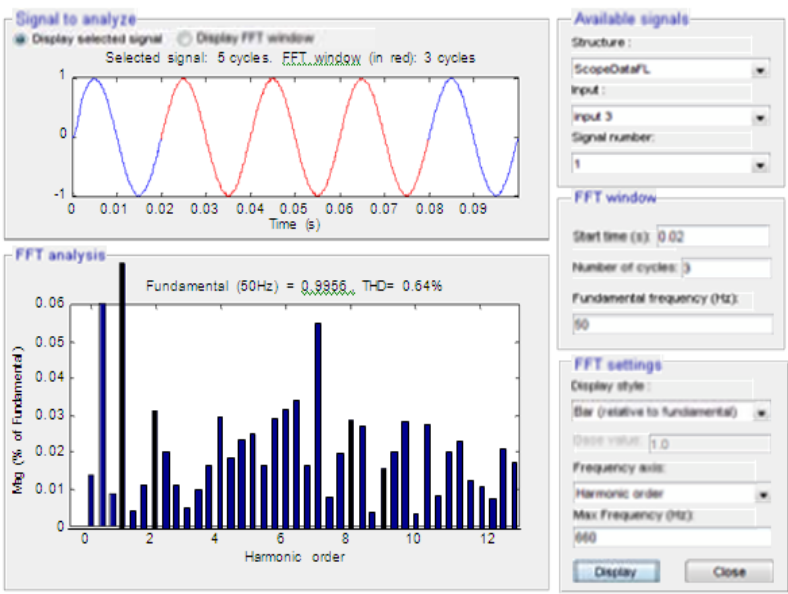

Figure 16. THD generated when FL controller is applied

\section{B. Effect of Energy Storage Capacities}

The ability of DVR to compensate voltage sag depends on the capacity of energy storage. Table IV shows the improvement of capability of DVR to mitigate voltage sag with respect to variation of energy storage capacities. At 100 Vdc energy storage, the DVR is no longer capable to mitigate sag and only able to improve voltage 0.0632 p.u higher. And it is clearly show that $110 \mathrm{Vdc}$ is the least voltage that capable to compensate voltage drop above 0.9 p.u.

\section{Effect of Transformer Ratings}

Table V shows the differences of THD generated before and after DVR mitigation with respect to changing of $\mathrm{kVA}$ ratings of injection transformer. The tabulated result shows that with higher $\mathrm{kVA}$ rating used, the THD generated will be less. DVR improve $46.55 \%$ in term of THD with $5 \mathrm{kV}$ Arating used compared to $1.5 \mathrm{kVA}$ rating. However, higher rating means that transformer is more expensive. 
Vol. 5, Issue 1, January 2017

TABLE IV Capability of DVR to Mitigate Sag

\begin{tabular}{|c|c|c|}
\hline $\begin{array}{c}\text { Energy } \\
\text { Storage } \\
\text { (Vdc) }\end{array}$ & $\begin{array}{c}\text { VL Before } \\
\text { Mitigation } \\
(\mathbf{p . u})\end{array}$ & $\begin{array}{c}\text { VL After } \\
\text { Mitigation } \\
(\mathbf{p . u})\end{array}$ \\
\hline 200 & 0.803 & 1.003 \\
\hline 180 & 0.8036 & 1.003 \\
\hline 150 & 0.803 & 0.9989 \\
\hline 120 & 0.8026 & 0.9545 \\
\hline 110 & 0.8026 & 0.9036 \\
\hline 100 & 0.8027 & 0.8659 \\
\hline
\end{tabular}

Table V. Effects of total harmonic distortion with Different KVA rating

\begin{tabular}{|c|c|c|}
\hline kVA & $\begin{array}{c}\text { THD Before } \\
\text { Mitigation \% }\end{array}$ & $\begin{array}{c}\text { THD After } \\
\text { Mitigation \% }\end{array}$ \\
\hline 1.5 & 0.8 & 0.64 \\
\hline 2 & 0.7 & 0.55 \\
\hline 3 & 0.56 & 0.4 \\
\hline 4 & 0.56 & 0.35 \\
\hline 5 & 0.55 & 0.31 \\
\hline
\end{tabular}

\section{CONCLUSIONS}

In this study, mitigating of unbalanced voltage sag by using coustom devices the modeling and simulation of DVR controlled by PI and FL Controller has been developed using Matlab/Simulink. For both controllers, the simulation result shows that the DVR compensates the sag quickly $(70 \mu \mathrm{s})$ and provides excellent voltage regulation. DVR handles all types, balanced and unbalanced fault without any difficulties and injects the appropriate voltage component to correct any fault situation occurred in the supply voltage to keep the load voltage balanced and constant at the nominal value. Both controllers show an excellent performance and generate low THD $(<5 \%)$. However, it can be seen that FL Controller gives better performance with THD generated with only $0.64 \%$ whilst PI generated $1.68 \%$ THD. However, other several factors that can affect the performance of DVR need to be addressed for enhancement of the output voltage. These factors are the energy storage capacity and transformer rating. From the simulation, it clearly shows the importance of these two factors and how they affect the performance of DVR. Therefore, when it comes to implementation, it is crucial to consider these factors, so that the performance of DVR is optimized.

\section{REFERENCES}

[1] Omar, R. Rahim, N.A. "New Control Technique Applied in Dynamic Voltage Restorer for Voltage Sag Mitigation" Industrial Electronics and Applications, 2009. ICIEA 2009. 4th IEEE Conference on
[2] Faisal, M.F. "Power Quality Management Program: TNB's Experience", Distribution Engineering, TNB 2005

[3] Wahab, S.W. Yusof, A.M. "Voltage Sag Mitigation Using Dynamic Voltage Restorer (DVR) System, ELEKTRIKA, 8(2), 2006, 32-37.

[4] IEEE Standard Board (1995), "IEEE Std. 1159-1995", IEEE Recommended Practice for Monitoring Electric Power Quality". IEEE Inc. New York.

[5] Kim H. "Minimal Energy Control for a Dynamic Voltage Restorer", In proceedings of the Power Conversion Conference, Osaka, Japan, 2002, pp. 428-433.

[6] V.K. Ramachandaramurthy, A. Arulampalam, C.Fitzer, C. Zhan, M. Barnes and N. Jenkins"Supervisory control of dynamic voltage restorers "IEE Proc.-Gener. Transm. Distrib. Vol. 151, No. 4, pp. 509-516, July 2004.

[7] P. Boonchiam and N. Mithulananthan, "Understanding of Dynamic Voltage Restorers through MATLAB Simulation," Thammasat Int. J. Sc. Tech., Vol. 11, No. 3, July-Sept 2006.

[8] Nise, N. S. "Control Systems Engineering" 5th Edition, John Wiley \& Son, Inc. 2008

[9] Mattavelli, P. Rossetto, L. Spiazzi, G. Tenti, P. "GeneralPurpose Fuzzy Controller for DC-DC Converter" IEEE Transactions on Power Electronics, Vol. 12, No. 1, January 1997.

[10] Nemati, M. Yousefian, H. A. Afshari, R. "Recognize The Role of A DVR in Power Systems" International Journal of Recent Trends in Engineering, Vol 2, No. 7, November 2009.

[11] Benachaiba, C. Ferdi, B. "Voltage Quality Improvement Using DVR", Electrical Power Quality and Utilization, Journal Vol. XIV, No. 1, 2008

\section{BIOGRAPHY}

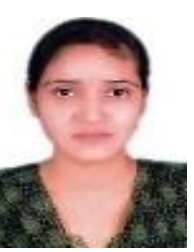

Miss Manjusha Hedau obtained the B.Tech Degree in Electrical and Power Engineering from Govt, College of Engg, Amravati (Amravati university) India in 2012.she pursing M.Tech Degree in Power Electronics and Power System from S.D. College of Engg. Selukate, Wardha. She is working as an Assistant professor in Electrical Engineering Department of Jagadambha College of Engineering and Technology, Yavatmal. Her research interests include electrical drives and power system analysis. 